Editorial: Hospital Metropolitano

ISSN (impreso) 1390-2989 - ISSN (electrónico) 2737-6303

Edición: Vol. 28 No 4 (2020) octubre - diciembre

DOI: https://doi.org/10.47464/MetroCiencia/vol28/4/2020/21-28

URL: https://revistametrociencia.com.ec/index.php/revista/article/view/92

Pág: 21-28

\title{
Malformación congénita de la vía aérea pulmonar. Reporte de un caso
}

\section{Congenital malformation of the pulmonary airway. Report of a case}

\section{Fabricio Macías Zambrano' (i), Hugo Garzón Ávila' (iD), Daniela Vela Merino ${ }^{2,3}$ (i) Andrea Santamaria ${ }^{2}$, Lizette Herdoiza Arroyo ${ }^{4}$}

\begin{abstract}
Gineco Obstetra, Médico Tratante del Servicio de Ginecología y Obstetricia del Hospital Metropolitano; Quito, Ecuador ${ }^{1,2}$ Posgrado de Ginecología y Obstetricia de la Pontificia Universidad Católica del Ecuador; Quito, Ecuador ${ }^{3}$ Médico Familiar, Máster en Gastroenterología y Nutrición Pediátrica; Investigadora Independiente; Quito, Ecuador ${ }^{4}$
\end{abstract}

\author{
Recibido: 01/05/2020 Aceptado: 20/09/2020 Públicado: 29/10/2020
}

\section{RESUMEN}

El objetivo de este estudio es realizar una revisión de la Malformación Congénita Pulmonar a propósito del caso de un feto de una paciente de 34 años que cursaba su segunda gesta, cuyo diagnóstico se realizó a la semana 30 de gestación. Además se realizó una revisión bibliográfica de la patología y de casos similares.

Palabras claves: Malformación congénita de la vía aérea pulmonar, malformación pulmonar congénita, lobectomía, toracotomía, cirugía pediátrica, malformación adenomatoidea quística, CCAM CPAM.

\section{ABSTRACT}

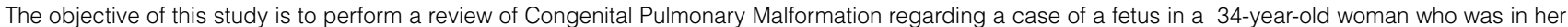
second pregnancy, whose diagnosis was made at week 30 of gestation. In addition, a bibliographic review of the pathology and similar cases was carried out.

Keywords: Congenital malformation of the pulmonary airway, congenital pulmonary malformation, lobectomy, thoracotomy, pediatric surgery, cystic adenomatoid malformation, congenital cyst adenomatoid malformation, CCAM, CPAM

Fabricio Macías Zambrano: Hugo Garzón Ávila: Daniela Vela Merino: Andrea Santamaría: Lizette Herdoíza Arroyo:

\section{IDs Orcid}

https://orcid.org/0000-0002-2496-220X https://orcid.org/0000-0003-1280-455 https://orcid.org/0000-0001-8215-8706 https://orcid.org/0000-0002-3049-9426 https://orcid.org/0000-0002-1024-7141

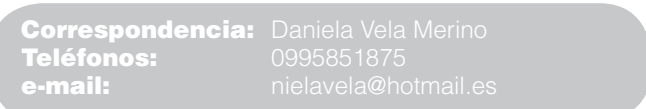




\section{INTRODUCCIÓN}

Las anomalías pulmonares congénitas abarcan una amplia gama de trastornos ${ }^{1,2}$. De estas se calcula que un 95\% son malformaciones congénitas de las vías aéreas pulmonares ${ }^{3}$, estas se caracterizan por un patrón anormal de las vías respiratorias lo que se atribuye a una alteración del componente epitelial de la yema bronquial, ocasionando crecimiento aumentado de estructuras bronquiales con una consecuente disminución de alvéolos durante la morfogénesis de ramificación pulmonar, esto causa que hayan quistes y / o áreas pulmonares adenomatosas ${ }^{3,4}$. Su patogenia es incierta, pero varios estudios sugieren un patrón próximo-distal defectuoso o alterado del epitelio caracterizado por ausencia de alveolos normales en la lesión y la formación de una masa pulmonar multiquística².

\section{Caso clínico}

Paciente femenina de 34 años de edad, sin antecedentes clínicos de importancia, antecedente de cesárea hace 5 años por compromiso del bienestar fetal. Acudió cursando su tercera gesta a la semana 30, se realizó ecografía obstétrica en la que se evidenció pulmón derecho fetal con imágenes multiquísticas (Imagen 1). Se contó con el consentimiento informado del paciente para el desarrollo de este procedimiento y publicación de este.
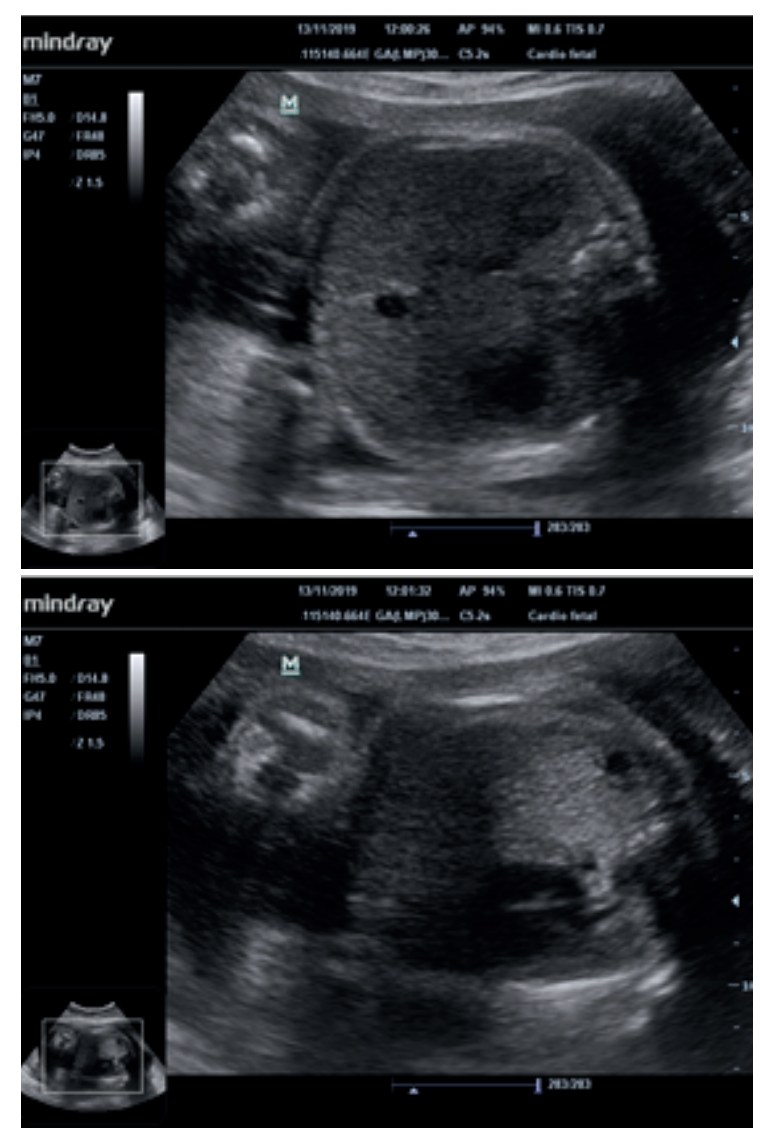

Imagen 1. Ecografía obstétrica a las 30 semanas

Fuente: Los autores
La resonancia magnética nuclear centrada en la cavidad torácica fetal, muestra pulmones desarrollados simétricos. En el pulmón derecho se evidencia un área de incremento de señal en las imágenes sensibles al líquido, con imágenes de aspecto microquístico. Las estructuras de la línea media no están desplazadas. La vía aérea superior principal impresiona respetada. Corazón de tamaño normal. No hay derrame pleural ni pericárdico. No se observan hernias diafragmáticas.

Las imágenes descritas en el pulmón lateralizadas a derecha son compatibles con malformación congénita de la vía pulmonar de aspecto microquístico (Imagen 2).

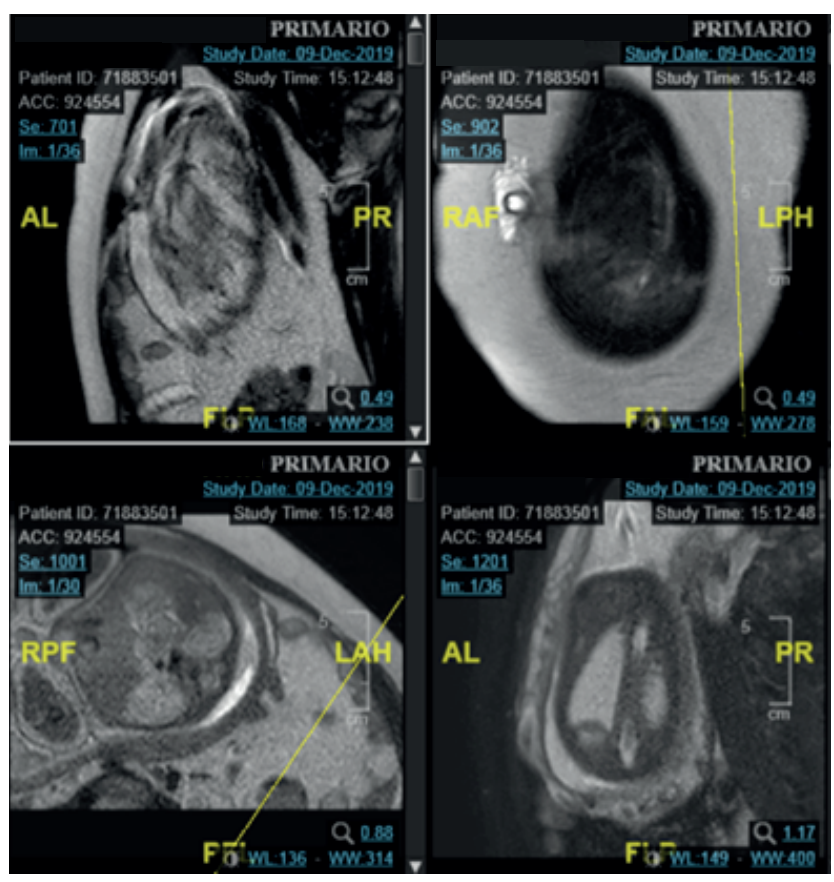

Imagen 2. Ecografía obstétrica a las 30 semanas

Fuente: Los autores

Se realiza cesárea programada a la semana 38,6 de gestación por cicatriz uterina previa, procedimiento sin complicaciones. Como hallazgos principales se evidencia líquido amniótico claro con grumos en moderada cantidad. Recién nacido de sexo masculino, peso 2715 gramos, talla 47 centímetros, perímetro cefálico 33.3 centímetros, APGAR 8/8, con Ilanto rápido, buen tono, frecuencia cardiaca mayor a 100 latidos por minuto, no ameritó maniobras de reanimación. Ingresa a cuidados intermedios para observación y realizar exámenes complementarios.

La radiografía de tórax del niño, se evidencia infiltrado de tipo mixto difuso en el campo pulmonar derecho, hiperinsuflación pulmonar izquierda, silueta cardiaca de tamaño normal, ángulos cardio y costofrénicos libres (Imagen 3). 


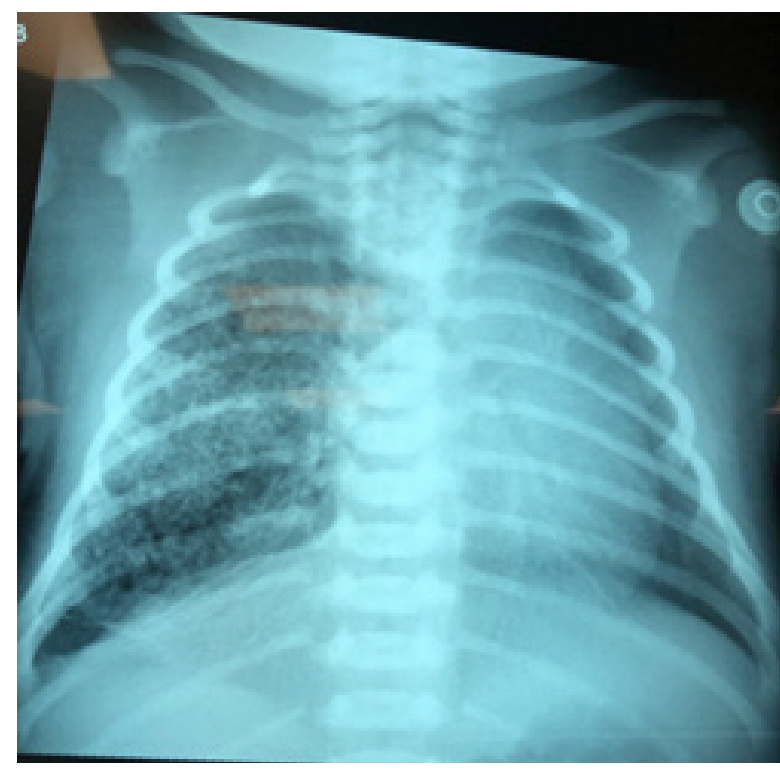

Imagen 3. Radiografía simple antero posterior de tórax

Fuente: Servicio de Imágenes. Hospital Metropolitano Quito, 2020.

En la tomografía axial computarizada se evidencia en pulmón derecho formaciones quísticas con aéreas confluyentes que distorsionan la arquitectura del lóbulo medio y segmento superior del lóbulo inferior, menores a 5 milímetros, hallazgos consistentes con malformación congénita de la vía aérea pulmonar (tipo III). Se aprecian áreas focales de incremento de la densidad, en probable relación con componentes atelectásicos asociados. Determina efecto de masa con desviación contralateral de las estructuras mediastinales (Imagen 4).

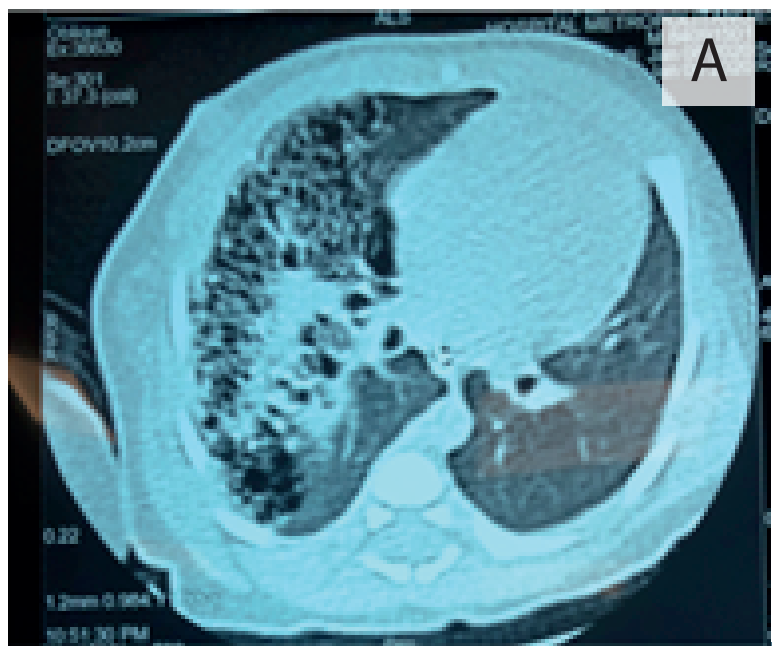

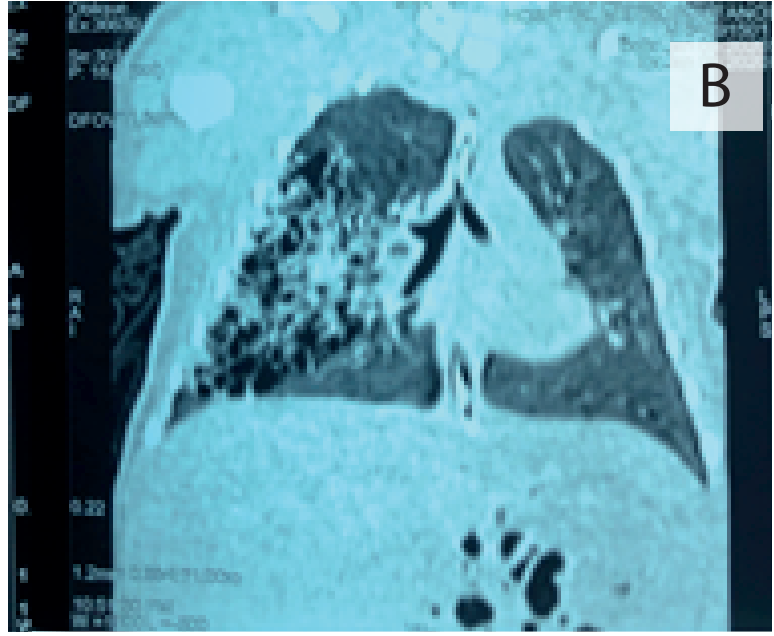

Imagen 4. Tomografía simple de tórax. A) Corte axial. B) Corte coronal.

Fuente: Servicio de Imágenes. Hospital Metropolitano Quito, 2020.

En el ecocardiograma se evidenció comunicación interauricular tipo ostium secundum de 0.3 centímetros y conducto arterioso permeable de $0.2 \times 0.18$ centímetros. Imágenes hipoecoicas en campos pulmonares. Insuficiencia tricuspidea y mitral leves. Presión arterial pulmonar $43 \mathrm{mmHg}$ con datos anatómicos de hipertensión pulmonar.

En la valoración por cirugía cardio torácica pediátrica a las 24 horas de nacido, el niño satura 100\% con oxígeno, frecuencia cardiaca 138 latidos por minuto, con taquipnea. Se decide tratamiento quirúrgico.

Se realiza toracotomía derecha, bilobectomía de segmento superior y medio, infiltración de nervios intercostales y colocación de tubo torácico, el procedimiento quirúrgico fue realizado sin complicaciones, con lo siguientes hallazgos:

1. Hiperinsuflación de lóbulo superior derecho con múltiples quistes en los segmentos basal y apical con afectación del lóbulo medio hipoplásico, que no permite su separación.

2. Lóbulo inferior funcional e hipoplásico.

3. Mal desarrollo del drenaje venoso pulmonar. 


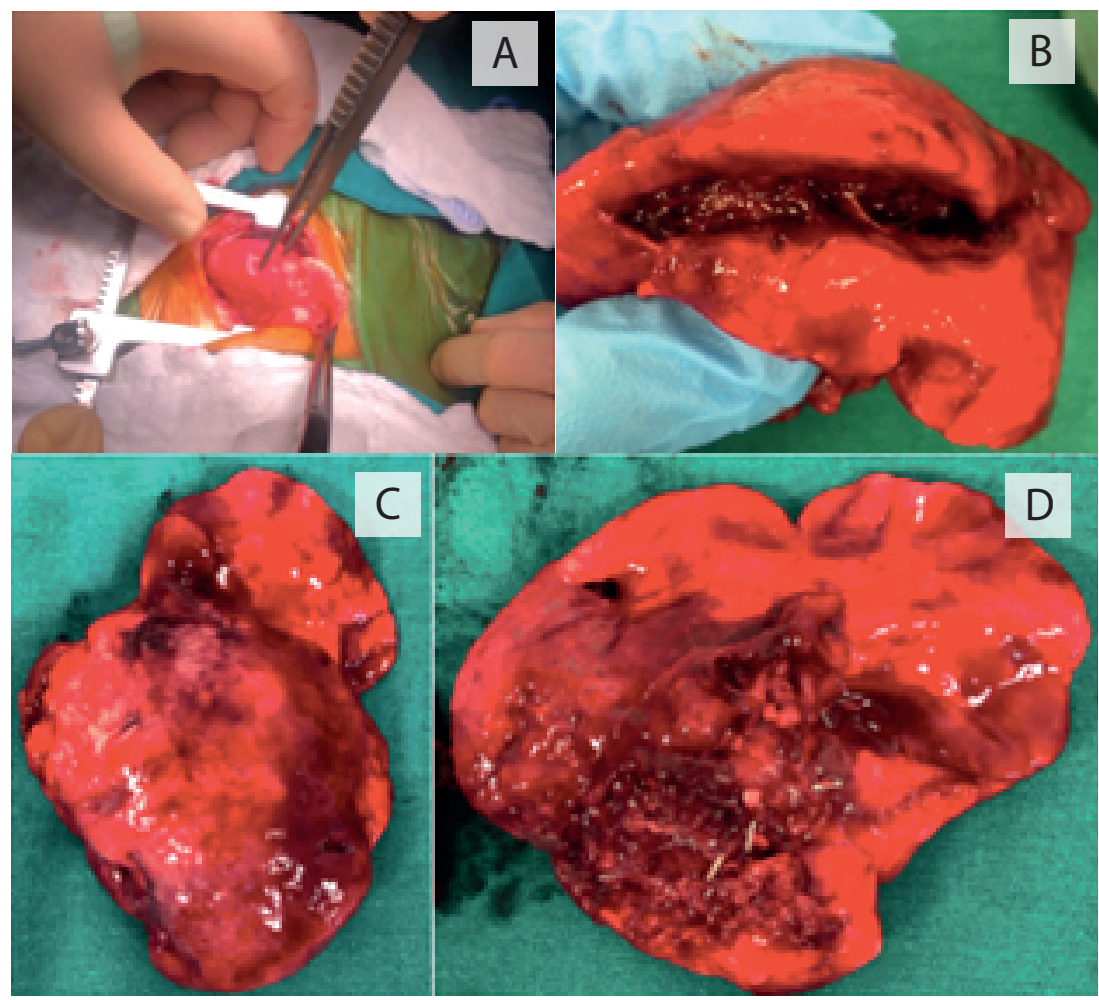

Imagen 5. A) Imagen transquirúrgica de segmento a resecar. B) Cara anterior. C) Cara superior. D) Cara inferior.

Fuente: Foto tomada en Quirófano. Hospital Metropolitano Quito, 2020.

El estudio histopatológico, se reporta pieza quirúrugica de 26.3 gramos, lóbulo superior de $6 \times 5 \times 1.5$ centímetros, lóbulo medio de $6 \times 2.5 \times 0.7$ centímetros, pleura visceral lisa marrón con áreas blanquecinas. En el corte seriado del lóbulo superior se observan varias formaciones quísticas de entre 0,1 y 0.5 centímetros, con contenido de aspecto purulento, en el tercio inferior se encuentra una área hepatizada de 1 centímetro. El corte del lóbulo medio impresiona hepatizado con coloración marrón. Se cataloga como una malformación pulmonar congénita tipo III, constituida por estructuras tipo bronquiolar, tapizadas por epitelio cuboidal y separadas por estructuras alveolares adenomatoides o sólidas.

El neonato presenta evolución favorable, se realiza controles radiográficos.

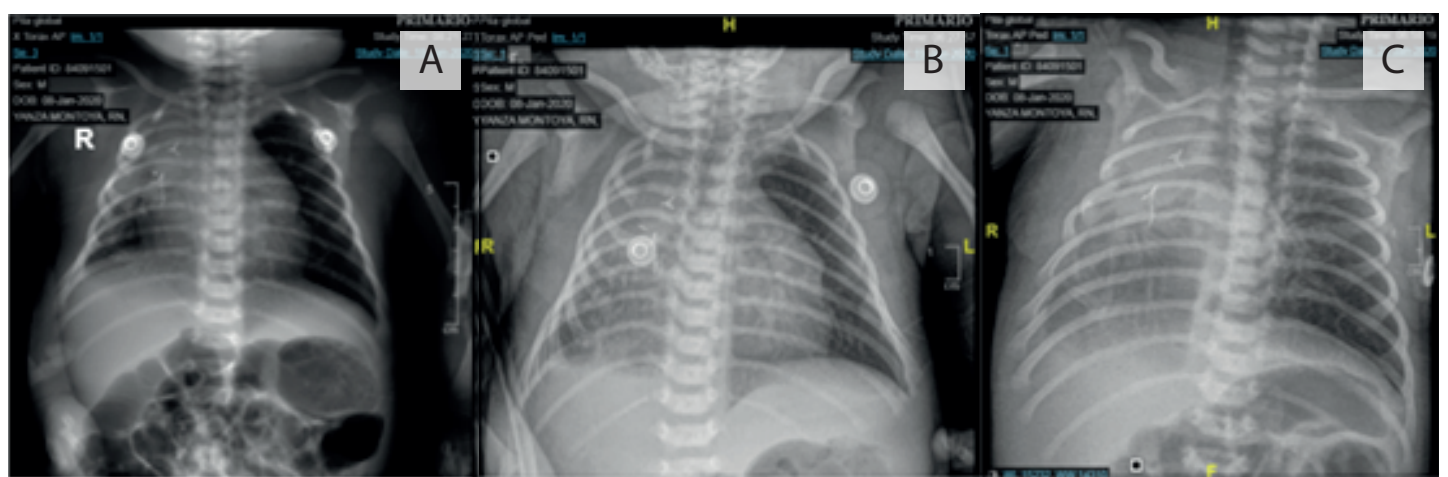

Imagen 6. Controles por radiografía simple de tórax. Días Postquirúrgicos: A) Día 8, se evidencia volumen pulmonar derecho disminuido, opacidad pulmonar derecha de predominio apical, clips metálicos por antecedente quirúrgico en hemitórax derecho, opacidad parcial de ángulos diafragmáticos, tráquea y mediastino con retracción hacía la derecha. B) Diá 9, se retira tubo torácico, se evidencia incremento a nivel de las opacidades del campo pulmonar derecho y signos de derrame pleural. C) Día 12, opacidad difusa en hemitórax derecho con clips quirúrgicos metálicos proyectados en este sitio. Mediastino central. Corazón impresiona de tamaño normal. Hiperinsuflación del pulmón izquierdo. Ángulos cardio y costofrénicos libres. Opacidad parcial de ángulos diafragmáticos. Tráquea y mediastino con retracción hacía la derecha.

Fuente: Servicio de Imágenes. Hospital Metropolitano Quito, 2020. 
Posteriormente el neonato presenta evolución favorable y es dado de alta con oxígeno.

\section{REVISIÓN BIBLIOGRÁFICA}

Las anomalías pulmonares congénitas abarcan una amplia gama de trastornos, como la malformación congénita de las vías respiratorias pulmonares (CPAM; anteriormente conocida como malformación adenomatoidea quística congénita), secuestro broncopulmonar, atresia bronquial, quiste broncogénico y enfisema lobular congénito ${ }^{1}$.

\section{Definición}

Las malformaciones congénitas de las vías aéreas pulmonares o CPAM son malformaciones pulmonares del desarrollo poco frecuentes ${ }^{2}$. Se caracterizan por un patrón anormal de las vías respiratorias que se se deben a una alteración del componente epitelial de la yema bronquial, ocasionando sobrecrecimiento de estructuras bronquiales y disminución de alveolos durante la morfogénesis de ramificación pulmonar y pueden conducir posiblemente a quistes y / o áreas pulmonares adenomatosas ${ }^{2,3}$.

\section{Epidemiología}

Aunque en general es poco común, aproximadamente el $95 \%$ de la enfermedad congénita del pulmón quístico se explica por la malformación congénita de la vía aérea pulmonar. La incidencia de CPAM se estima que es de 1 en 10000 a 1 en 35000 nacimiento ${ }^{4}$.

\section{Etiología}

Las CPAM se producen esporádicamente. Su for- mación no está relacionada con factores maternos como la raza, la edad o la exposición. Se han realizado algunos estudios que muestran el predominio masculino en lesiones que se presentan en la primera infancia. En general, estas malformaciones ocurren esporádicamente sin predisposición genética (excepto el Tipo 4) que se han asociado con un síndrome de blastoma pleuropulmonar familiar (PPB) y sin asociación con factores maternos ${ }^{4}$.

\section{Fisiopatología}

La patogenia de la CPAM es incierta, pero varios estudios sugieren un patrón próximo-distal defectuoso o alterado del epitelio. Esta alteración podría resultar de una señalización defectuosa entre el epitelio y el mesénquima subyacente durante el desarrollo pulmonar, lo que da como resultado una ausencia de alvéolos normales en la lesión y la formación de una masa pulmonar multiquística. La evidencia sugiere que genes como el factor de crecimiento de fibroblastos 10 (FGF10), el factor de transcripción tiroidea 1 (NK2 homeobox 1) y la región determinante del sexo Ybox 2 (SOX2), que son responsables del crecimiento y la diferenciación celular, están asociados con la afección'1.

\section{Clasificación}

La malformación congénita de la vía aérea pulmonar tiene cinco subtipos principales que han sido descritos y asignados por la clasificación de Stocker. Cada tipo se origina en una parte diferente del árbol bronquial, lo que posteriormente conduce a una diferenciación histopatológica distinta, características clínicas, potencial maligno y pronóstico ${ }^{4}$.

Tabla 1. Clasificación de Stocker

\begin{tabular}{|c|c|c|c|c|c|}
\hline \multirow{2}{*}{ Prevalencia } & Tipo 0 & Tipo 1 & Tipo 2 & Tipo 3 & Tipo 4 \\
\hline & $1-3 \%$ & $60-65 \%$ & $15-20 \%$ & $5-10 \%$ & $5-10 \%$ \\
\hline \multirow{3}{*}{ Macroscópicamente } & Traqueo-bronquial & Bronquial y bronquiolar & Bronquiolar & $\begin{array}{l}\text { Bronquiolar - } \\
\text { bronquiolo } \\
\text { respiratorio }\end{array}$ & Acinar \\
\hline & $\begin{array}{l}\text { Quistes pequeños, } \\
\text { con un diámetro } \\
\text { máximo de } 0,5 \mathrm{~cm} \text {. }\end{array}$ & $\begin{array}{l}\text { Quistes distintos de } \\
\text { paredes delgadas de } \\
2 \text { a } 10 \mathrm{~cm} \text { de diámetro. } \\
\text { Suelen ser únicos, pero } \\
\text { pueden estar } \\
\text { multiloculados. }\end{array}$ & $\begin{array}{l}\text { Múltiples quistes } \\
\text { de } 0,5 \text { a } 2 \mathrm{~cm} \text {, sin } \\
\text { efecto de masa. }\end{array}$ & $\begin{array}{l}\text { Generalmente } \\
\text { involucra y } \\
\text { expande un lóbulo } \\
\text { completo y } \\
\text { comprime los otros } \\
\text { lóbulos. Estas } \\
\text { lesiones suelen } \\
\text { ser sólidas versus } \\
\text { quísticas. }\end{array}$ & $\begin{array}{l}\text { Quistes periféricos } \\
\text { de pared delgada } \\
\text { que son } \\
\text { multiloculados. }\end{array}$ \\
\hline & $\begin{array}{l}\text { Epitelio } \\
\text { pseudoestratificado } \\
\text { ciliado. }\end{array}$ & $\begin{array}{l}\text { Epitelio columnar } \\
\text { seudoestratificado, } \\
\text { ciliado. }\end{array}$ & $\begin{array}{l}\text { Epitelio cilíndrico } \\
\text { o columnar } \\
\text { ciliado. }\end{array}$ & $\begin{array}{l}\text { Epitelio cuboidal } \\
\text { no ciliado. }\end{array}$ & $\begin{array}{l}\text { Epitelio cuboidal } \\
\text { con múltiples } \\
\text { arterias y arteriolas } \\
\text { en el mesénquima. }\end{array}$ \\
\hline Histopatología & $\begin{array}{l}\text { Las células } \\
\text { mucosas y el } \\
\text { cartílago están } \\
\text { presentes, pero el } \\
\text { músculo } \\
\text { esquelético está } \\
\text { ausente }\end{array}$ & $\begin{array}{l}45 \% \text { de estas lesiones } \\
\text { contiene células } \\
\text { productoras de moco, y } \\
\text { una capa fibromuscular } \\
\text { delgada puede estar } \\
\text { presente debajo del } \\
\text { epitelio. }\end{array}$ & $\begin{array}{l}\text { Las células se- } \\
\text { cretoras de moco } \\
\text { y el } \\
\text { cartílago están } \\
\text { ausentes. }\end{array}$ & $\begin{array}{l}\text { Las células } \\
\text { secretoras de } \\
\text { moco y el cartílago } \\
\text { están } \\
\text { ausentes. }\end{array}$ & $\begin{array}{l}\text { No células } \\
\text { mucosas ni } \\
\text { músculo } \\
\text { esquelético. }\end{array}$ \\
\hline
\end{tabular}




\begin{tabular}{|c|c|c|c|c|c|}
\hline $\begin{array}{l}\text { Manifestaciones } \\
\text { clínicas }\end{array}$ & $\begin{array}{l}\text { Incompatible con la } \\
\text { vida. }\end{array}$ & $\begin{array}{l}\text { Al nacimiento es la } \\
\text { polipnea; en el niño } \\
\text { mayor, la dificultad } \\
\text { respiratoria y las } \\
\text { infecciones } \\
\text { frecuentes. }\end{array}$ & $\begin{array}{l}\text { Aparecen en } \\
\text { el primer año de } \\
\text { vida; se } \\
\text { acompaña de } \\
\text { agenesia renal y } \\
\text { malformaciones } \\
\text { cardiovasculares. }\end{array}$ & $\begin{array}{l}\text { Dificultad respira- } \\
\text { toria grave o } \\
\text { muerte en el } \\
\text { período neonatal. }\end{array}$ & $\begin{array}{l}\text { Dificultad } \\
\text { respiratoria desde } \\
\text { el nacimiento, } \\
\text { neumonía y } \\
\text { neumotórax a } \\
\text { tensión. }\end{array}$ \\
\hline Pronóstico & & $\begin{array}{l}\text { Tiene potencial } \\
\text { maligno. }\end{array}$ & $\begin{array}{l}\text { Bueno, no tiene } \\
\text { potencial } \\
\text { maligno. }\end{array}$ & $\begin{array}{l}\text { Dificultad respira- } \\
\text { toria grave o muer- } \\
\text { te en el período } \\
\text { neonatal. }\end{array}$ & $\begin{array}{l}\text { Fuertemente } \\
\text { asociado } \\
\text { con malignidad, } \\
\text { especialmente con } \\
\text { blastoma } \\
\text { pleuropulmonar. }\end{array}$ \\
\hline
\end{tabular}

Modificado de: Mehta PA, Sharma G. Congenital Pulmonary Airway Malformation. [Updated 2019 Dec 4]. In: StatPearls [Internet]. Treasure Island (FL): StatPearls Publishing; 2020 Jan-. Available from: https://www. ncbi.nlm.nih.gov/books/NBK551664/

\section{Diagnóstico}

Las manifestaciones clínicas son variables. Muchos pacientes son identificados durante una ecografía prenatal de rutina. Actualmente se considera que aproximadamente $25 \%$ de pacientes con diagnóstico prenatal son sintomáticos al nacimiento ${ }^{8}$.

\section{Valoración Prenatal}

CPAM es una de las lesiones pulmonares más frecuentemente identificadas en el periodo prenatal, sin embargo la prevalencia al nacimiento es baja. El diagnóstico se realiza en la mayoría de casos mediante ecografía. La apariencia ecográfica varía desde lesiones de apariencia quística halladas incidentalmente hasta el compromiso pulmonar masivo $^{9}$. La presencia de macroquistes o de un tumor de apariencia sólida en el tórax fetal sugieren la presencia de esta patología. En el segundo trimestre, los macroquistes (>5 mm) son anecoicos y están rodeados de parénquima pulmonar hiperecogénico. Las lesiones microquísticas $(<5 \mathrm{~mm})$ tienen apariencia de tumor sólido, homogéneo de apariencia hiperecogénica en comparación con el parénquima circundante. Pueden ocurrir también lesiones mixtas $^{10}$. La clasificación prenatal se basa precisamente en el diámetro de los quistes y puede ser macro o microquística si miden más o menos de $5 \mathrm{~mm}^{11}$. Es importante considerar que aproximadamente el 50 $\%$ de lesiones tienden a presentar regresión ecográfica espontánea, sin embargo, en la mayoría de ellos siguen siendo identificables en estudios de imagen post natal ${ }^{12}$.

La evaluación cuantitativa tiene utilidad para predecir el desarrollo prenatal de la enfermedad, para lo cual se utiliza:

- Relación del volumen de la malformación pulmonar congénita de la vía aérea (CVR): Se obtiene calculando el volumen del tumor pulmonar usando la fórmula de volumen de un óvalo y extrapolando a edad gestacional. Para realizar esta extrapolación se debe dividir el volumen del tumor para la circunferencia cefálica. CVR $=$ Alto $x$ diámetro AP $\times$ diámetro transverso x 0.52 (constante) / circunferencia cefálica ${ }^{13}$.

- Relación Tumor a Tórax (MTR): La relación entre el diámetro transverso del tumor y el diámetro transversal del tórax. La medición se realiza en un corte axial en el cual se visualiza la imagen de cuatro cámaras del corazón.

- Relación Pulmón - Corazón observada a esperada (Observada/esperada LHR): Descrita inicialmente como un valor predictor en la hernia diafragmática congénita ${ }^{14}$.

\section{Exámenes complementarios}

Doppler color y Doppler poder: La valoración de la circulación puede ser útil en el diagnóstico diferencial $^{15}$.

Ecocardiografía fetal: Se recomienda en todas las pacientes en el momento del diagnóstico para descartar anomalías cardíacas. Tiene utilidad también para valorar aquellos fetos con alto riesgo o quienes ya han desarrollado hidrops ${ }^{15}$.

Resonancia Magnética: Es útil para corroborar el diagnóstico y mejorar la especificidad que tiene la ecografía. Se sugiere su uso para delinear adecuadamente la anatomía normal de la anormal cuando todo el parénquima pulmonar está comprometido, en la presencia de hidrops o lesiones bilaterales y cuando no hay certeza diagnóstica ${ }^{15}$.

Tomografía axial computarizada: Se recomienda realizarla de manera postnatal para caracterizar las lesiones ${ }^{21}$. 


\section{Diagnóstico diferencial}

Se puede evidenciar hallazgos ecográficos similares en otras patologías pulmonares o de vía aérea en las ecografías prenatales ${ }^{1}$.

Tabla 2. Diagnóstico diferencial de la Malformación Pulmonar Congénita ${ }^{5}$

\begin{tabular}{|c|c|}
\hline Patología & Características \\
\hline Quiste broncogénico & $\begin{array}{l}\text { - No se comunica con el árbol } \\
\text { bronquial, no están llenos de aire. }\end{array}$ \\
\hline Secuestro pulmonar & $\begin{array}{l}\text { - } \quad \text { Suministro arterial sistémico. } \\
\text { Las lesiones híbridas pueden } \\
\text { presentarse con malformación } \\
\text { congénita de la vía aérea pulmo- } \\
\text { nar y características de secues- } \\
\text { tro. }\end{array}$ \\
\hline $\begin{array}{l}\text { Hernia diafragmática } \\
\text { congénita }\end{array}$ & $\begin{array}{l}\text { - Asas intestinales o vísceras ab- } \\
\text { dominales dentro de un hemitó- } \\
\text { rax. } \\
\text { Puede haber desplazamiento del } \\
\text { mediastino. }\end{array}$ \\
\hline $\begin{array}{l}\text { Enfisema lobular } \\
\text { congénito } \\
\text { (sobreinsuflación } \\
\text { lobular congénita) }\end{array}$ & $\begin{array}{l}\text { - Segmento pulmonar hiperlúcido } \\
\text { e hiperinsuflado. } \\
\text { Sin componentes quísticos ni só- } \\
\text { lidos. }\end{array}$ \\
\hline $\begin{array}{c}\text { CHAOS (Congenital } \\
\text { High Airway } \\
\text { Obstruction Syndrome }\end{array}$ & $\begin{array}{l}\text { - Vía aérea dilatada que define el } \\
\text { nivel de la obstrucción (laringe } \\
\text { versus tráquea). } \\
\text { Hiperecogenicidad pulmonar bi- } \\
\text { lateral. }\end{array}$ \\
\hline
\end{tabular}

Modificado de: Lee EY, Boiselle PM, Cleveland $\mathrm{RH}$. Multidetector CT Evaluation of Congenital Lung Anomalies. Radiology. 2008;247 (3): 632-48. doi:10.1148/radiol.2473062124.

\section{Tratamiento}

\section{Manejo prenatal}

Si la presencia de CPAM es aislada, el riesgo de aneuploidía es igual a la población general, pero se incrementa en aquellos fetos que tienen hidrops o anormalidades múltiples. Se debe evaluar el requerimiento de procedimientos invasivos de manera individual, en especial en casos que se presente hidrops fetal o polihidramnios ${ }^{17,21}$.

Seguimiento mediante estudios de imagen: Se sugiere evaluaciones ecográficas seriadas cada una a cuatro semanas para valorar cambios en el tamaño del tumor pulmonar, en la CVR así como el desarrollo de polihidramnios e hidrops ${ }^{16,20}$.

Intervenciones no invasivas: Los corticosteroides son la única alternativa farmacológica de manejo en CPAM, se usan principalmente en enfermedad microquística pero se han usado también en enfermedad macroquística. Se ha demostrado que pueden revertir el hidrops y mejorar el desenlace fetal ${ }^{18}$. La betametasona materna se administra en dos dosis de 12 mg por vía intramuscular con 24 h entre do$\operatorname{sis}^{21}$.

Intervenciones invasivas: Todos los procedimientos invasivos descritos para la resolución de CPAM deben considerarse experimentales y de investigación. Los estudios se limitan a reporte de casos y estudios observacionales pequeños. Las pacientes deben ser tratadas por especialistas en medicina materno - fetal con experiencia en procedimientos fetales invasivos. El éxito del procedimiento invasivo depende de la experiencia quirúrgica, anestesia materna óptima, relajación uterina adecuada, histerotomía, exposición fetal, monitoreo fetal intraoperatorio así como técnicas confiables para la reaproximación de las membranas y pared uterina ${ }^{19}$.

Manejo postnatal: No se dispone de protocolos estandarizados para el manejo de la CPAM, el manejo en casos asintomáticos es controversial ${ }^{21}$.

Se consideran características de alto riesgo a la presencia de: placentomegalia, ecocardiografía fetal anormal, eversión del diafragma, desplazamiento mediastínico severo o hipoplasia pulmonar ${ }^{21}$.

En general se considera que si el feto que no responde adecuadamente a una intervención fetal no quirúrgica y tiene menos de 32 semanas de edad gestacional, se puede realiar una lobectomía fetal, en especial en casos de hidrops. En algunos casos se ha visto resolución del hidrops en 1 a 2 semanas, el retorno del mediastino a la línea media en 3 semanas y un crecimiento notable del pulmón en el útero. Actualemnte se acude a la lobectomía fetal como tratamiento en casos de respuesta desfavorable a la terapia con esteroides maternos, y sigue siendo una opción factible en los centros fetales para quienes no responden a otras terapias ${ }^{21}$.

La lobectomía se puede realizar como cirugía fetal, como parto operatorio controlado (cesárea) con lobectomía fetal en soporte placentario: tratamiento intraparto ex-útero (EXIT) o postnatalemnte ${ }^{21}$.

\section{Conclusiones}

La CPAM es una patología poco frecuente. Su diagnóstico, seguimiento y tratamiento inutero son controversiales y no se dispone de protocolos que estandaricen su manejo.

Los esteroides prenatales deben administrarse a madres portadoras de un feto con una lesión pulmonar quística congénita microquística con factores de alto riesgo ${ }^{21}$

Se debe ofrecer derivación toracoamniótica o descompresión cuando un feto tiene una lesión pulmonar quística congénita macroquística con factores e hidrops de "alto riesgo"21. 


\section{REFERENCIAS BIBLIOGRÁFICAS}

1. Wong K, Flake A, Tibboel D, Rottier R, Tam P. Congenital pulmonary airway malformation: advances and controversies. Lancet Child Adolesc Health. 2018 Apr;2(4):290-297. doi: 10.1016/S23524642(18)30035-X. Epub 2018 Feb 17.

2. Leblanc $C$ et al. Congenital pulmonary airway malformations: state-of-the-art review for pediatrician's use. Eur J Pediatr. 2017 Dec;176(12):1559-1571. doi: 10.1007/s00431-017-3032-7. Epub 2017 Oct 19 .

3. Palmer J, Montalvo A, Uro-Huerta H, Gutiérrez S, Madriñan J. Malformación congénita de la vía aérea pulmonar. Informe de un caso y revisión de la literatura. Acta Pediatr Mex 2010;31(2):70-74

4. Mehta PA, Sharma G. Congenital Pulmonary Airway Malformation. [Updated 2019 Dec 4]. In: StatPearls [Internet]. Treasure Island (FL) StatPearls Publishing; 2020 Jan-. Available from: https://www.ncbi. nlm.nih.gov/books/NBK551664/

5. Garzi A et al. Congenital Cystic Adenomatoid Malformation of the Lung Tipe II: Three Cases Report. Transl Med UniSa. 2019 Jan 12;20:4-8. eCollection 2019 Jul-Dec

6. Disu E et al. Congenital pulmonary airway malformation: A case report of a rare cause of neonatal respiratory distress and review of the literature. Niger J Clin Pract. 2019 Nov;22(11):1621-1625. doi: 10.4103/ njcp.njcp_20_19.

7. Van Koningsbruggen S, Ahrens F, Brockmann M, et al. Congenital cystic adenomatoid malformation type 4. Pediatr Pulmonol 2001; $32: 471$

8. Parikh DH, Rasiah SV. Congenital lung lesions: Postnatal management and outcome. Semin Pediatr Surg 2015; (24):160.

9. Duncombe GJ, Dickinson JE, Kikiros CS. Prenatal diagnosis and management of congenital cystic adenomatoid malformation of the lung Am J Obstet Gynecol 2002; (187):950.

10. Levine D, Barnewolt CE, Mehta TS, et al. Fetal thoracic abnormalities: MR imaging. Radiology 2003; (228):379.

11. Adzick NS, Harrison MR, Crombleholme TM, et al. Fetal lung lesions: management and outcome. Am J Obstet Gynecol 1998; (179):884
12. Kunisaki SM, Ehrenberg-Buchner S, Dillman JR, et al. Vanishing fetal lung malformations: Prenatal sonographic characteristics and postnatal outcomes. J Pediatr Surg 2015; (50):978.

13. Crombleholme TM, Coleman B, Hedrick H, et al. Cystic adenomatoid malformation volume ratio predicts outcome in prenatally diagnosed cystic adenomatoid malformation of the lung. J Pediatr Surg 2002; (37):331.

14. Schott S, Mackensen-Haen S, Wallwiener M, et al. Cystic adenomatoid malformation of the lung causing hydrops fetalis: case report and review of the literature. Arch Gynecol Obstet 2009; (280):293.

15. Flanagan S, Rubesova E, Hintz S, et al. Prenatal imaging of bronchopulmonary malformations: Is there a role for late third trimester fetal MRI? Pediatr Radiol 2013; (43):205

16. Gowda M, Gupta S, Ali A, Paranthaman S. Locating the Level and Extent of Congenital High Airway Obstruction: Fluid in the Airway Tract as Reference Points. J Ultrasound Med 2017; (36):2179.

17. Adzick NS, Harrison MR, Crombleholme TM, et al. Fetal lung lesions: management and outcome. Am J Obstet Gynecol 1998; (179):884.

18. Derderian SC, Coleman AM, Jeanty C, et al. Favorable outcomes in high-risk congenital pulmonary airway malformations treated with multiple courses of maternal betamethasone. J Pediatr Surg 2015; 50:515.

19. Peranteau WH, Adzick NS, Boelig MM, et al. Thoracoamniotic shunts for the management of fetal lung lesions and pleural effusions: a single-institution review and predictors of survival in 75 cases. J Pediatr Surg 2015; 50:301.

20. Salinas J. Patología Pulmonar Congénita: Evaluación y Manejo Perinatal. Revista Médica Clínica de las Condes 2018; Vol. 27. Núm. 4.

21. Downard CD, Calkins CM, Williams RF, Renaud EJ, Jancelewicz T, Grabowski $\mathrm{J}$ et al. Treatment of congenital pulmonary airway malformations: a systematic review from the APSA outcomes and evidence based practice committee. Pediatric Surgery International. 2017 Sep 1;33(9):939-953. https://doi.org/10.1007/s00383-017-4098-z.

22. Lee EY, Boiselle PM, Cleveland RH. Multidetector CT evaluation of congenital lung anomalies. Radiology. 2008;247 (3): 632-48. doi:10.1148/radiol.2473062124. 